\title{
Mexicanos endeudados en la crisis hipotecaria en California
}

\author{
Magdalena Villarreal
}

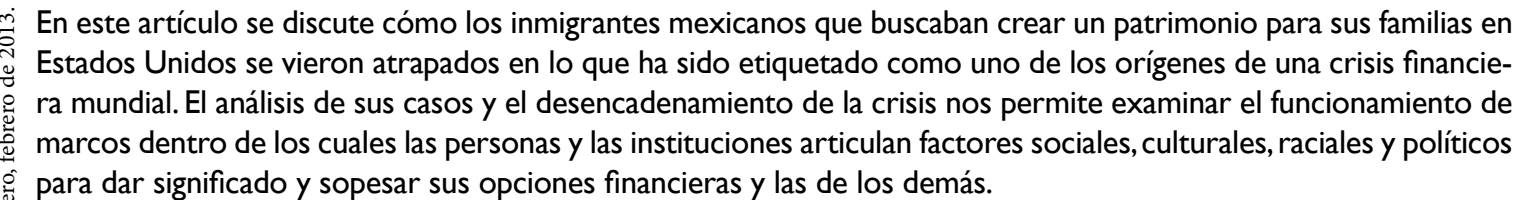

PALABRAS CLAVE: crisis hipotecaria, préstamos de alto riesgo, endeudamiento, discriminación social, marcos de cálculo

\section{Endebted Mexicans in the Mortgage Crisis in California}

In this paper we discuss how Mexican immigrants, seeking wealth for themselves and their families in the United States, got trapped into what has come to be branded as one of the origins of a world financial crisis. The analysis of their cases and the unfolding of the crisis allow us to examine the workings of frameworks within which people and institutions articulate social, cultural, racial and political factors to signify and weigh their financial options as well as those of others.

KEYWORDS: mortgage crisis, subprime loans, indebtedness, social discrimination, frameworks of calculation

Magdalena Villarreal: Centro de Investigaciones y Estudios Superiores en Antropología Social-Occidente,

Guadalajara, Jalisco, México

magdalena.villarreal@gmail.com 


\section{INTRODUCCIÓN}

$\mathrm{L}$ as convulsiones características de la crisis financiera mundial, que explotó en $2008,{ }^{1}$ comenzaron a percibirse un par de años antes. En julio de 2007 se dio a conocer en los medios masivos de comunicación el desencadenamiento de grandes pérdidas en los mercados bursátiles a nivel global. El desastre sobrevino tras la revelación de lo que muchos sabían, pero preferían ignorar: que ciertos instrumentos financieros, cuyo éxito en el mercado había sido significativo, estaban basados en créditos hipotecarios que nunca serían cubiertos. Tales instrumentos, diseñados por ingenieros en finanzas de Wall Street para satisfacer el apetito de riesgo de millones de inversionistas, habían generado jugosas ganancias a muchos pero naufragaban al descubrirse desprovistos de respaldo. En California, uno de los estados de la Unión Americana críticamente involucrados en la crisis hipotecaria, una gran cantidad de los préstamos impagables habían sido suscritos por afroamericanos e inmigrantes mexicanos.

El caos que se desató revela aspectos esenciales del funcionamiento de los sistemas financieros actuales, en particular de sus formatos de cálculo. La medición del capital, por ejemplo, que la mayoría suponemos un cálculo sencillo, está plagada de ambigüedades y áreas grises. Para empezar, la promesa de valor futuro suele incluirse como capital. Esto es visto como normal en la vida económica. Como señala Steve Keen (2001: 141-145), el valor de una máquina, considerado usualmente una forma de capital, se calcula según el precio y las ganancias que se espera obtener con ella. Es decir, el valor monetario

\footnotetext{
${ }^{1}$ Como se sabe, las dimensiones de la crisis han sido de gran magnitud. Se habla de que ha sido la peor crisis financiera desde la Gran Depresión de los años treinta, causó el colapso de grandes instituciones financieras y cuantiosas pérdidas en los mercados de valores alrededor del mundo. Esto contribuyó a la crisis de deuda europea y aún afecta las posibilidades de recuperación de numerosas economías nacionales.
}

está basado en lo que la máquina producirá. La crisis hipotecaria nos ha hecho agudamente conscientes de lo que ya sabíamos: que el valor de una casa incluye estimaciones de las posibilidades de que su valor se incremente en el futuro. Las expectativas de incremento de valor pueden, de acuerdo con los códigos predominantes, tomarse en cuenta como "capital".

La utilización de tales estimaciones, como equi$t y,{ }^{2}$ para obtener préstamos -incluso en casos en los que ya había una primera hipoteca que no había sido del todo cubierta- no se consideraba problemática. Se suponía que una vez que la casa fuese vendida podría pagarse el monto total. En ciertas instancias, sin embargo, se constató que esta forma de raciocinio se había llevado demasiado lejos. Fue el caso de Enron, ${ }^{3}$ una compañía en la que las ganancias prometidas aparecieron en los registros contables como ganancias reales. Aunque este tipo de prácticas han sido castigadas, eran y siguen siendo comunes. Cantidad de estimaciones similares se observaron en lo que se llamó la "burbuja inmobiliaria”. Se estimulaba el otorgamiento de préstamos bajo un cálculo de ganancias: entre más se prestaba, mayores ganancias se obtenían. En resumen, podría decirse que la misma aritmética guió el comportamiento de quienes participaban en los mercados bursátiles, se vendían y revendían las promesas de utilidades provenientes de deudas, con frecuencia en paquetes que, como explicaré más delante, podrían incluir sólo derivados de las transacciones.

En las líneas siguientes tomo el caso de una familia "compuesta", integrada por inmigrantes mexicanos, el cual arroja luz sobre los flujos dinámicos de dinero y las relaciones sociales que circulan entre estos inmigrantes, que facilitan al mismo tiempo

\footnotetext{
${ }^{2}$ Valor residual -el valor del bien menos las deudas que se tienen sobre éste- - Se toma en cuenta el incremento en valor de la vivienda según su cotización en el mercado.

${ }^{3}$ Corporación productora de energía con base en Texas que empleaba a 21000 personas antes de declararse en bancarrota en 2001. Mediante una serie de maniobras contables fraudulentas, la compañía había logrado ser considerada una de las más prometedoras en Estados Unidos.
} 
que restringen sus esfuerzos económicos cotidianos. Es importante tener en mente estos flujos monetarios y sociales y los circuitos que habitan para comprender la naturaleza social y cultural de sus transacciones financieras. Pese a vivir historias y circunstancias similares, los miembros de este grupo social realizan prácticas financieras diferentes y enfrentan condiciones distintas en su incursión en el mercado de la vivienda. Sólo uno de los tres integrantes del grupo que adquirió una casa perdió su inversión y otro se atrasó en algunos pagos, aunque pudo reestructurar su deuda en varias ocasiones, pero los tres tuvieron que recurrir a remesas inversas — dinero que les enviaron de México- ${ }^{4}$ para cumplir con sus pagos. Ése es el tema de la primera parte del artículo. En la segunda parte se analiza el proceso que condujo a la crisis y sus implicaciones. Se evidencian distintos regímenes de valor que operan de manera simultánea en estos escenarios. Retomo el término de régimen de valor ${ }^{5}$ con cierta hesitación, dada su evocación a sistemas estructurados y rígidos. Sin embargo, lo considero útil en tanto resalta cómo la valoración de bienes, servicios e interacciones se reproduce de forma diferencial en asociación con alineamientos particulares de categorías. Ciertos órdenes más o menos establecidos adquieren legitimidad al recurrir a símbolos y significados institucionalizados, forjados en referencia a creencias y valores predominantes. Es aquí donde se

\footnotetext{
${ }^{4}$ Más adelante hablaré de las remesas inversas con más detalle. En este punto es importante mencionar que muy pocas veces han sido tomadas en cuenta en los estudios de la migración. Un estudio interesante realizado por BBVA Bancomer (2010: 33) calculó los gastos que hace México en la educación de los migrantes antes de que dejen el país y encontró que entre 1994 y 2008 México transfirió en promedio seis millones de dólares al año a Estados Unidos, lo que equivale a medio punto porcentual de su producto interno bruto (РIB).

${ }^{5}$ Véase Appadurai (1986: 4 y 15), quien utiliza este concepto y explica, de acuerdo con las agudas observaciones de Simmel sobre dinero e intercambio, que el término no implica que cada acto de intercambio de mercancías suponga compartir de manera completa supuestos culturales, sino que el grado de coherencia de valor puede ser bastante variable entre las situaciones y entre una mercancía y otra.
}

formulan necesidades y deseos. Los regímenes de valor enmarcan los cálculos ${ }^{6}$ respecto de cómo evaluar y enfrentar sus predicamentos.

La cuestión que pretendo subrayar es que la identificación de lo que puede convertirse en un activo valioso, las precisiones acerca de su valor y las explicaciones que conciernen a la manera en que el valor de hoy se relaciona con lo que se espera para mañana no pueden calcularse fácilmente con números. Nociones de promesa, confiabilidad, peligro y riesgo son críticas para este tipo de cálculos y adquieren una importancia especial en mercados volátiles, que suelen ser los más buscados por los inversionistas porque sus fluctuaciones proporcionan la oportunidad de obtener altas utilidades. Aunque en las transacciones se entiende que ciertas instituciones financieras y regulatorias del mercado son confiables, todos están agudamente conscientes de que entrañan un riesgo que no es fácil calcular. El miedo es por tanto un componente importante de las transacciones financieras y se establecen parámetros para limitar los riesgos. Estos parámetros incorporan categorías de los solicitantes de préstamos que se consideran más susceptibles al riesgo y los comportamientos azarosos. Tales clasificaciones incluyen necesariamente criterios sociales y culturales.

En este contexto los mexicanos y los afroamericanos, entre otras categorías, en Estados Unidos fueron catalogados como clientes "de alto riesgo", no elegibles para préstamos ordinarios. La mayoría de ellos recibieron préstamos subpreferenciales —subprime - ${ }^{7}$ que, según algunas fuentes, podían

\footnotetext{
${ }^{6} \mathrm{Al}$ concentrarme en cálculos no pretendo decir de ninguna manera que las personas siempre calculen sus opciones explícitamente para tomar mejores decisiones, como se infiere desde la perspectiva de elección racional - rational choice theory-. Los cálculos, como los trato aquí, son a menudo un ejercicio de evaluación $a$ posteriori, y con más frecuencia suposiciones que se dan por hecho, como lo sugiere la noción de la doxa de Bourdieu (1994).

${ }^{7}$ Utilizo a propósito la traducción literal subpreferencial en lugar del término comúnmente usado en español, hipotecas de alto riesgo, para subrayar que las hipotecas no son intrínsecamente de alto riesgo, sino que son consideradas así bajo criterios que incluyen en gran medida categorizaciones de tipo social y racial. Éste es uno de los argumentos que expongo a lo largo del artículo.
} 


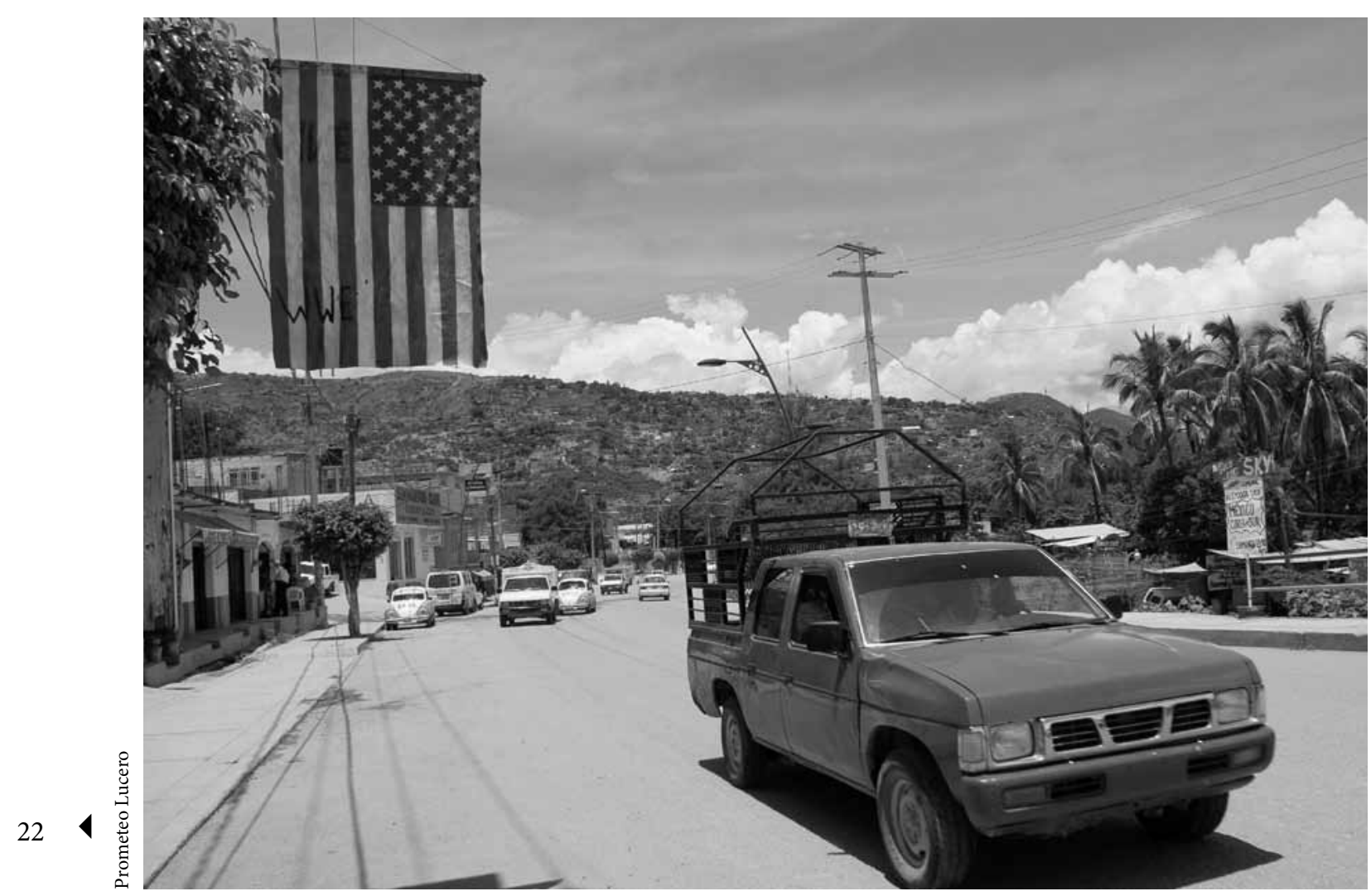

Tlapa de Comonfort, Guerrero, ciudad que comunica a todos los pueblos indígenas de La Montaña.

tener un costo cinco veces mayor que un préstamo estándar. Así, los bancos se "aseguraban" contra el riesgo de mora, lo que paradójicamente fue uno de los factores principales que provocaron las carteras vencidas. Pueden cuestionarse muchas cosas acerca de la manera en la que se llevó a cabo la contabilidad de la falta de pago de los préstamos — como por qué el dinero que los bancos recibieron como pagos iniciales se dejó fuera de los cálculos, al igual que el dinero obtenido por las ventas de los paquetes de deuda-, pero ése no es el tema de este artículo, ya se han escrito bastantes páginas y pronunciado suficientes discursos políticos acerca de la avaricia y el comportamiento inmoral de muchos banqueros.

Como era de esperarse, se ha llegado a la conclusión de que debería ponerse orden. El sistema financiero debe estar mejor regulado y ser monitoreado más seriamente. Todo eso es muy razonable, pero lo que nos interesa para los propósitos de este artículo es que ese orden es concebido en concordancia con ciertos regímenes de valor compuestos predominantemente - aunque no siempre de manera explícita- por conjuntos de convenciones y valoraciones no cuestionados que proporcionan forma y formato a las transacciones financieras. Esto se manifiesta en las plataformas desde las que se predican verdades: el ángulo desde el cual la economía y quienes participan en ella han de ser juzgados y analizados.

Aquello que debe percibirse como riesgoso, lo que es prometedor y lo que se puede estimar como confiable se evalúa - a menudo con sofisticados estudios- de acuerdo con fórmulas específicas que, por muy técnicas que sean, no pueden evitar apoyarse en criterios sociales y culturales dentro de 
los cuales tienen sentido ciertas reglas y regulaciones. ${ }^{8}$ Se reconocen determinadas jerarquías que representan secuencias de prioridades: lo que es más relevante y debe tomarse en consideración en un cálculo y lo que es "ruido incidental" y debe ser excluido. Las convenciones no cuestionadas - por ejemplo, los mecanismos por medio de los cuales ciertos grupos sociales no son considerados dignos de confianza - son a menudo importados de otros ámbitos de la vida social, aunque influyen en ellos, y en el proceso se le da un formato al alcance que tendrán los cálculos. Desde esta perspectiva, la definición misma y la clasificación de la deuda pueden variar dentro de y entre estos regímenes de valor y marcos de cálculo. La deuda puede ser calculada en algunos escenarios como un pasivo y en otros como un activo. ${ }^{9}$ Éste es el tema central del artículo. A través del análisis del caso de los mexicanos atrapados en la crisis hipotecaria, mi objetivo es examinar el funcionamiento de los marcos dentro de los cuales las personas y las instituciones articulan factores sociales, culturales y políticos para dar significado y sopesar sus opciones financieras y las de los demás.

\section{EVA Y SU "FAMILIA COMPUESTA": ECONOMÍAS ENTRELAZADAS}

En sus vidas cotidianas las mujeres mexicanas que han emigrado a Estados Unidos tienen que enfrentarse al mismo tiempo con varias economías que cruzan diferentes tipos de fronteras, incluyendo las nacionales. Tal es el caso de Eva, una mujer que

\footnotetext{
${ }^{8}$ Los sistemas financieros están hasta cierto punto limitados por esas reglas y regulaciones, pero no necesariamente determinados por ellas o al menos no sólo por ellas.

${ }^{9}$ Por ejemplo, en una evaluación típicamente capitalista se considera "sensato" que las compañías operen con cierto nivel de deuda. Aquellas que nunca han utilizado préstamos podrían ser clasificadas como demasiado conservadoras, sin visión de futuro e incluso ineficientes. A nivel individual, cuando se solicita un préstamo, un consumidor con buen historial de crédito tiene ventajas sobre los consumidores que nunca han contraído deudas.
}

lucha por organizar su vida en California, pero que aún depende de México para su subsistencia. A diferencia de muchos otros mexicanos, Eva no estaba en una situación económica difícil cuando cruzó la frontera de Estados Unidos. Sin embargo, sí tenía grandes expectativas de encontrar nuevas oportunidades de ganar dinero.

A principios de los años ochenta, su padre era propietario de una pequeña librería en la ciudad de México y pudo financiar su viaje a Tijuana, en el norte de México, donde Eva viviría con su madrina. Trabajó dos años como recepcionista en el hotel de su madrina, el cual servía como punto de encuentro entre migrantes y "coyotes" 10 por su cercanía con la línea fronteriza. Ahí conoció a quien ahora es su marido, oriundo del estado de Jalisco, en el occidente de México, y que había vivido en Estados Unidos durante diez años. A mediados de los ochenta, Eva y su esposo cruzaron la frontera hacia California. Su economía seguía estando íntimamente ligada a su familia y a sus lazos regionales en México. Eva habla de dos fases de su vida: cuando era una "princesa" (sic) en México y su vida de casada en Estados Unidos, la cual divide a su vez en dos partes: cuando no tenía casa y trabajaba en el campo, y ahora que tiene casa y vive con el miedo de perderla.

Después de casarse, Eva y su esposo se unieron a lo que llamo una "familia compuesta", muy común entre los inmigrantes mexicanos en Estados Unidos, quienes se apiñan en una sola casa para compartir gastos - en especial la renta- y ahorrar dinero. Esta "familia" se integraba por: Eva y su esposo; Violeta, hermana del esposo de Eva; Ernesto, amigo de Violeta en su comunidad de origen; Enriqueta - hermana del exmarido de Violeta-, su esposo René, sus tres hijos, su sobrina - hija de una hermana que había muerto- y su hermano Julián. En total había dos parejas, cuatro niños, una mujer que

\footnotetext{
${ }^{10}$ Los "coyotes" ayudan a los migrantes a cruzar ilegalmente al "otro lado" - Estados Unidos-. En ese tiempo cobraban hasta 400 dólares por hacerlo. En fechas recientes esta cantidad se ha incrementado.
} 
había dejado un hijo y una hija con su suegra en México, un hombre soltero y otro que había dejado a su mujer e hijos en México. El grupo cambió de residencia y de composición varias veces, según el trabajo disponible. En ocasiones habitaron en una casa de dos recámaras, otras veces se separaron y algunos vivieron en los campos donde trabajaban mientras otros pernoctaban en sus vehículos. A veces se les unía alguien más: la madre y el hermano de René, la esposa de Ernesto, el sobrino de Violeta, etc. También algunos de ellos se unieron a otros grupos. Primero residieron en Santa María, una localidad al norte de Los Ángeles donde había varios productores de verduras y legumbres, así como familias de trabajadores de cuatro estados de México: Michoacán, Guerrero, Jalisco y Guanajuato. Santa María había crecido demográficamente gracias a la inmigración de trabajadores - en su mayoría mexicanos- que iban a Estados Unidos en busca de trabajo aunque, a diferencia de otras localidades rurales del centro de California, seguía teniendo un porcentaje importante de población de anglos. Los principales productores de esta área pertenecían a este sector.

Al principio, Eva y su marido sólo encontraron alojamiento en áreas segregadas de la pequeña ciudad, pero luego se mudaron más cerca del centro. ${ }^{11}$ Trabajaban en los campos agrícolas recolectando fresas en la costa central de California y al terminar la temporada iban al norte a cosechar manzanas en Oregon. Sobra decir que en este tipo de empleo no tenían contrato ni prestaciones y se les remuneraba sólo por día trabajado. Compartían una casa, compraban alimentos y abarrotes juntos y resolvían sus problemas de transporte como un grupo. René,

\footnotetext{
${ }^{11}$ Como Palerm señala acertadamente: "los trabajadores (migrantes) de hoy no viven en colonias, vecindarios y los campos de labor del pasado. Ocupan el núcleo de las comunidades, pueblos y ciudades agrícolas de California, donde se han constituido en la mayoría de la población local. Es como si las colonias del pasado hubieran sido recuperadas y hubieran tragado a pueblos y ciudades americanos enteros en donde se les había recibido antes como apéndices marginados" (Palerm, 2007: 10).
}

quien tenía más tiempo que los demás viviendo en Estados Unidos, contaba con vehículo y obtenía un ingreso extra al cobrar a los demás su traslado al trabajo. Aunque no era barato, nadie se quejaba, era un gasto necesario, ya fuera que se lo pagaran a él o a alguien más.

En este contexto, los miembros del grupo tuvieron que enfrentar al mismo tiempo diferentes escenarios financieros, cada uno con sus propias reglas, significados y valores, guiados por regímenes de valor no explícitos relacionados con la vida social. Por un lado, el propósito declarado de su arduo trabajo y sus sacrificios era ganar dinero para sus familias en México. Todos los integrantes adultos del grupo enviaban dinero a México en una u otra ocasión, pero sus obligaciones eran tanto sociales como monetarias. Tenían que hacer patente su preocupación por los familiares que permanecían en su comunidad de origen. Sus redes sociales en México implicaban ciertas reglas y roles de género, incluyendo la responsabilidad de ayudar a la familia, en particular si la situación económica del migrante era buena. De acuerdo con los códigos locales, se consideraba vergonzoso mostrarse como pobres - pues eso equivaldría a admitir que la gran empresa migratoria había sido un fracaso-, por lo que estaban obligados a enviar dinero a su familia, la cual era clasificada como "pobre" y "necesitada", aunque a veces no era el caso. Las cantidades de dinero enviadas, la periodicidad del envío y las maneras en las que se hacían las remesas eran estimadas dentro de estos marcos de cálculo. Sólo Ernesto enviaba dinero a México de manera sistemática, pero nunca lo suficiente para cubrir los gastos de su familia. Su esposa se dedicaba a labores agrícolas en México para asegurar la alimentación de sus hijos.

Sin embargo, todos cumplían con requerimientos específicos de su familia en México: dinero para llevar a la abuela al doctor, comprar zapatos para los niños, pagar cuotas comunitarias, asegurar la tenencia de la tierra, etc. También se esperaba que siguieran normas sociales y culturales de conducta como esposa, madre, hermano o hermana, tanto 
con sus familiares en Estados Unidos como con los de México. Aunque Violeta estaba separada de su esposo - el hermano de Enriqueta-, sus relaciones con otros hombres eran cuidadosamente observadas no sólo por su excuñada sino también por su propia familia y amigos, cuyos chismes podían viajar muy rápido. Y si Enriqueta gastaba demasiado dinero en ropa o su esposo compraba un nuevo automóvil la noticia se conocería pronto en México, donde su familia esperaba que cooperara más para pagar los gastos médicos de su madre $y$, de ser posible, ayudara a su hermana, cuyo esposo había sufrido un accidente. Tales normas de género y de otro tipo impusieron ciertas restricciones en cuanto al uso del tiempo y los tipos de gastos considerados adecuados.

Por otro lado, había que hacerse cargo de la dinámica del grupo mismo. Para algunos, como Ernesto, el miembro más reciente del grupo, resultó difícil compartir los costos, ya que estaba desesperado por ganar tanto dinero como fuera posible antes de regresar a México. Esto creó algunas tensiones al interior del grupo, en el que, además de contribuir para comprar alimentos y abarrotes, se esperaba que a veces compartiera con los demás o pagara la cerveza o algún otro "lujo". Enriqueta y su esposo proporcionaban información crítica en cuanto a contactos y oportunidades de trabajo. Fue así que el grupo formuló -o reformuló- los marcos de cálculo y las normas de intercambio. A través de ese tipo de redes los inmigrantes mexicanos adquirieron información fundamental sobre la vida social y financiera en Estados Unidos.

El esposo de Eva era el único miembro del grupo que tenía sus documentos en orden, al haber obtenido recientemente la categoría de "residente", que aunque no otorga los mismos derechos que la ciudadanía, confiere legalidad a su estancia en Estados Unidos. Los hijos varones de Enriqueta habían nacido en Estados Unidos, pero su sobrina todavía estaba como "ilegal", como la mayoría de los integrantes del grupo. Eva ayudó a su esposo a abrir una cuenta bancaria. No podía tener una a su nombre, pero aprendió rápidamente los procedimientos y adquirió habilidad para realizar los trámites. La cuenta les servía a todos para cobrar cheques, lo que para la mayoría de los inmigrantes era una tarea difícil, y a menudo tenían que acudir a tiendas o a pequeños supermercados de la localidad para cambiar sus cheques a cambio de una cuota. ${ }^{12}$

Actuar al mismo tiempo en escenarios económicos diversos es parte de la vida cotidiana, pero los actores están posicionados de manera diferente dentro de esos escenarios y su posicionamiento afecta el alcance de sus cálculos. Por ejemplo, su situación de inmigrantes ilegales restringía los cálculos de riesgo de algunos de los miembros de la familia compuesta, al grado de que ciertas actividades que podrían haber sido viables no eran siquiera tomadas en cuenta. Paradójicamente, en los campos agrícolas -donde la mayoría de los integrantes adultos de la familia trabajó durante sus primeros años en Estados Unidos- eran los mexicanos quienes se ocupaban con frecuencia de las etapas más riesgosas de la producción. Problemas como el clima y los precios del mercado hacen que la producción agrícola sea una empresa azarosa y que las compañías tiendan a evitar los segmentos más propensos a las pérdidas, por lo que recurren a menudo a diferentes formas de contratos de aparcería - sharecropping - con mexicanos que buscan una oportunidad de lograr el "sueño americano". Además de las ganancias por refrigeración, empaque y venta, los inversionistas pueden beneficiarse de deducciones fiscales otorgadas a la agricultura.

${ }^{12}$ Es interesante ver que algunos dueños de tiendas incluso actúan como "prestamistas" para los productores, que les piden que paguen cheques emitidos por ellos, pero que eviten cobrarlos ellos mismos hasta que tengan fondos suficientes en su cuenta para cubrirlos. Otros productores no pagan con cheques, lo que significa que este dinero no pasa por sus registros contables formales y por tanto no es considerado para impuestos y beneficios. Sin embargo, los inmigrantes indocumentados prefieren que les paguen en efectivo, ya que de cualquier manera no recibirían los beneficios y pueden ahorrarse la comisión que los cuentahabientes bancarios les cobrarían por cambiarlos. 


\section{ADQUIRIR UNA CASA: EL "SUEÑO AMERICANO" Y LA ECONOMÍA DE LA DEUDA}

La adquisición de una casa no estaba originalmente en los planes de la gran mayoría de los inmigrantes mexicanos en California. Su objetivo era trabajar duro, ganar dinero y volver a casa. Esto se ajustaba muy bien a los intereses de los empleadores, quienes preferían una renovación constante de mano de obra joven y fuerte. Sin embargo, los productos agrícolas de primor que se cultivan en California requieren también un alto nivel de destreza. Con las nuevas tecnologías, las tierras producen tres cosechas al año. Los buenos trabajadores son contratados por las mismas compañías todo el año, lo que estimula a los inmigrantes a establecerse de manera permanente (Palerm, 2007; Hernández, 2010: 7083). Por otro lado, desde el punto de vista de los inmigrantes, la esperada "fortuna" que llevarán a casa es difícil de conseguir y es muy humillante volver, como ellos dicen, "con las manos vacías". Así, pasan los años con la expectativa de que las cosas mejorarán. Con el tiempo, los hijos crecen acostumbrados a la forma de vida estadounidense y se torna complicado regresar a México.

Es difícil establecer con precisión cuándo se toma la decisión de comprar una casa. Por lo general optan por adquirir primero una pequeña casa rodante — traila - que estacionan en el jardín de un amigo o un pariente. Eso fue lo que hicieron Eva y su esposo. Cuando Eva descubrió que estaba embarazada, insistió en mudarse de la vivienda de la familia compuesta. Compraron una pequeña casa rodante que instalaron en el jardín del mismo domicilio. De esta manera, tenían cierta independencia pero seguían contando con el apoyo de los miembros de la familia. Compraron la casa rodante con dinero que

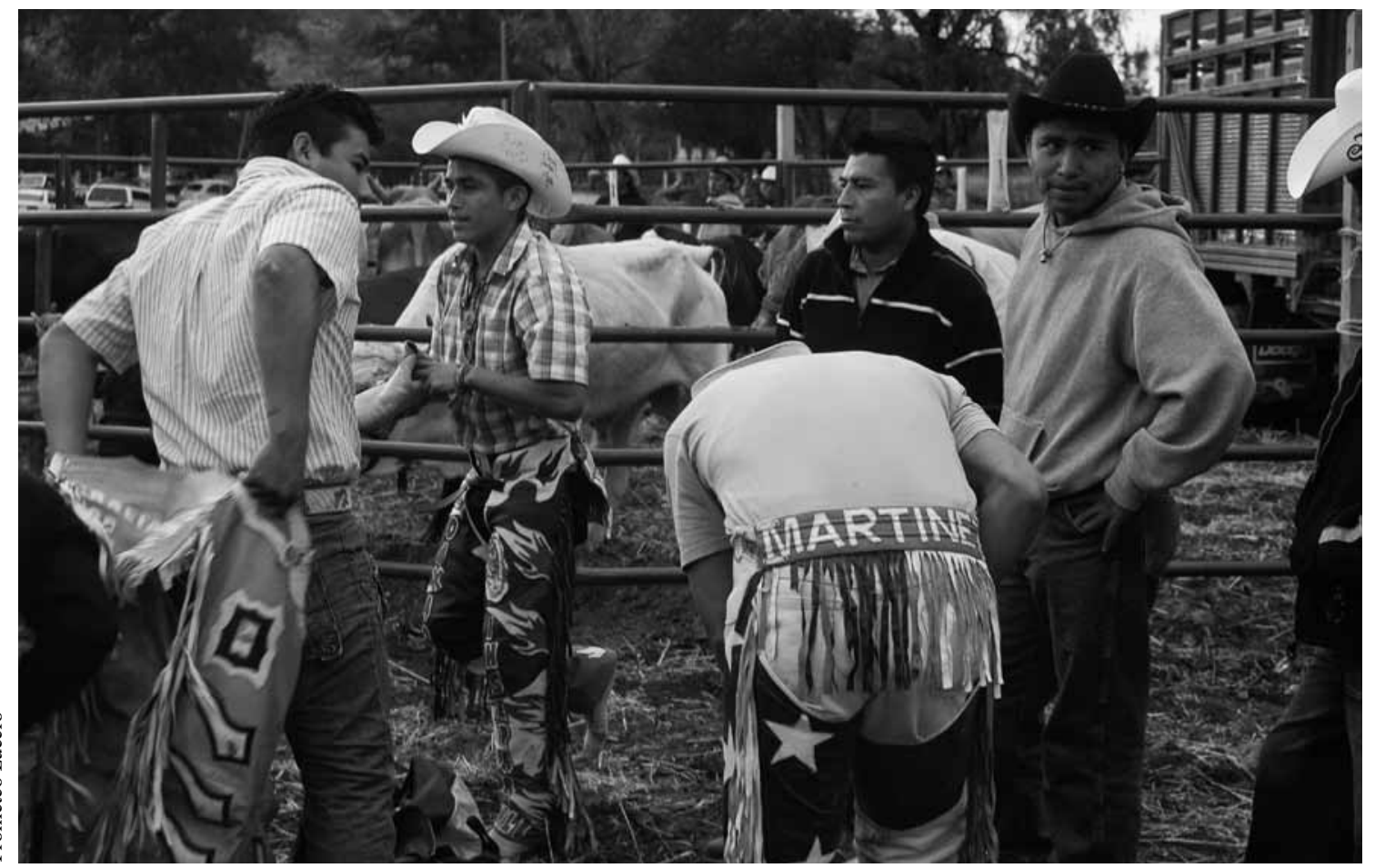

Festejo de la Virgen de Guadalupe en El Espinal, Oaxaca, el 12 de enero. Durante esta temporada arriban visitantes de Puebla y otros municipios oaxaqueños, así como muchos migrantes que viven fuera de la comunidad. 
les prestó la madrina de Eva, quien vivía en México. Ese tipo de préstamos eran, decía Eva con una sonrisa, como "préstamos del gobierno", lo que significaba que podían pagarlos o no. Su madrina nunca le cobraba intereses y casi siempre le decía que podía quedarse con el dinero. También les prestó dinero para que su esposo pudiera comprar herramientas y hacer trabajos de construcción, como reparaciones y extensiones de casas. El problema era que, aunque su marido era bueno en su trabajo y contaba con estatus "legal" en Estados Unidos, no podía registrarse como constructor porque sólo había estudiado tres años de educación primaria en México. Uno de los requisitos para obtener ese registro era la capacitación y para ello necesitaba algunos antecedentes educativos y hablar inglés. Era difícil trabajar sin estar registrado. Temía que si lo descubrían trabajando sin registro le quitaran sus documentos migratorios. Así, aunque trabajaba todo el día haciendo reparaciones domésticas y pudo comprar una camioneta para transportar materiales de construcción, lo hacía "bajo el agua" y tenía que cobrar mucho menos de lo que cobraban otros.

A principios de los años noventa a Enriqueta y a su esposo les ofrecieron comprar una casa. Como su nivel de ingresos no les permitía "calificar" para un préstamo, la adquirieron en copropiedad con Julián, el hermano de Enriqueta, y su cuñado. La copropiedad era entonces muy común entre los inmigrantes mexicanos. Al juntar sus nombres se agregaban sus ingresos y así pudieron cumplir con los criterios para "calificar" para un préstamo. A pesar de que en ese tiempo los agentes inmobiliarios y funcionarios bancarios no tenían una política de crédito tan agresiva como la que adoptarían en la década siguiente, ignoraban intencionalmente ciertas restricciones en el caso de los inmigrantes, siempre y cuando tuvieran dinero para pagar el enganche. De esta manera los agentes recibirían comisiones y los funcionarios bancarios se allegarían más clientes, quienes durante los primeros dos años pagarían los intereses y servicios de la deuda sin abonar al capital.
En este caso, un compadre que vivía en México les prestó dinero a Enriqueta y a su marido para cubrir el enganche. Si bien en sentido estricto dicho monto no podría considerarse como una remesa inversa, es importante hacer notar que no pagaron intereses sobre ese préstamo. $\mathrm{Al}$ igual que en muchas otras transacciones de país a país, la expectativa era que la relación seguiría siendo fuerte, lo que requería no sólo simple reciprocidad —que incluía por supuesto a la familia del compadre- sino también el mantenimiento de las redes y, como se mencionó, la obligación de seguir ciertas normas y conductas. Tales normas y conductas eran muy distintas a las que se habrían esperado de ellos en un escenario bancario. Aunque en ambos casos se esperaría confianza y lealtad, los significados y los valores detrás de esas nociones variaban. Los códigos con los que se formulaban esas transacciones eran diferentes.

Al principio Enriqueta, su esposo, sus hijos y su sobrina, Violeta, Julián, el hermano y la madre de René vivían en esa casa. Todos ayudaban con los pagos: Violeta en forma de renta; con muchos sacrificios, "amarrándose la tripa", como dicen, y trabajando turnos dobles, Enriqueta y René pudieron ahorrar suficiente dinero para pagar a los otros dos copropietarios su parte y continuar haciendo pagos mensuales ellos mismos -15 años después siguen rentando una parte de la casa para cubrir estos gastos-. De acuerdo con sus cálculos, esto sigue siendo mejor que pagar renta. Esa casa y la que lograron construir en México - deshabitada salvo durante las pocas semanas que la visitan cada dos añosson la única herencia que dejarán a sus hijos.

Julián, por otra parte, consiguió un buen empleo en una plantación de brócoli. Su responsabilidad era administrar el rancho, lo que incluía hacerse cargo de la maquinaria, organizar la producción y supervisar a los trabajadores. Se casó y pronto pudo comprar una casa. Su empleo estable y sus ingresos relativamente altos le permitieron "calificar" para un préstamo. En 2004 todavía estaba pagando su casa, cuyo valor se había incrementado significativamente, cuando un consultor que iba a menudo al rancho y se había 
hecho su amigo le recomendó usar el valor residual - equity - de la casa - que se había incrementado debido al alza en el valor comercial de las viviendas- para obtener un préstamo. Como tenía varios años queriendo empezar su propio negocio, obtuvo un préstamo para comprar dos camiones. No fue difícil porque durante algún tiempo los bancos le habían lanzado múltiples ofertas de préstamos, y a pesar de que habría calificado para una hipoteca estándar, por su historial crediticio y sus ingresos, recibió un préstamo subpreferencial. Julián cree que esto ocurrió por su nacionalidad, pero también explica que no estaba familiarizado con las instituciones financieras y que ni siquiera sabía formular las preguntas pertinentes.

Cuatro años después, su negocio no había empezado a producir ganancias y el valor de su casa se había desplomado, lo que lo obligó a vender un terreno en México que había sido de su padre. Esto le causó problemas con sus hermanos, a quienes decepcionó profundamente que un patrimonio familiar chos años por esas tierras y le hubiera gustado que continuaran produciendo. Al ser el más joven, Julián tenía derecho a vender legalmente ese terreno, pero a sus hermanos les molestaron sus cálculos fríos y su falta de consideración hacia su madre, quien todavía estaba viva y podría haber rentado el terreno. Para empeorar las cosas, el dinero que Julián obtuvo de la venta del terreno no fue suficiente. Vendió la casa y se mudó a Arizona, donde él y su familia se fueron a vivir con su hermano, y todavía están luchando por pagar sus deudas. Su hermano se mudó después a Cancún, en México, y a veces le envía dinero para ayudarlo con los pagos. Éste es un ejemplo más de remesas inversas y de regímenes de valor diferentes que entran en juego.

Eva, por otra parte, siempre había soñado con tener una casa nueva. Creía apasionadamente en el "sueño americano" y pensaba que sus dificultades eran transitorias. En 2003 se encontró casualmente con una amiga que era agente inmobiliaria, quien la convenció de que podía comprar una casa. Su

amiga no la llevó a una vivienda para gente de bajos ingresos, sino a una residencia de nivel medio de aspecto elegante en San Isidro, cerca de la frontera con México. Eva dice que se enamoró inmediatamente de la casa, pero dudó en adquirirla, pues pensaba que estaría por encima de sus posibilidades. La agente inmobiliaria, una mexicana-estadounidense que había tenido que esforzarse para conseguir capacitación en su profesión, la convenció de que sólo tomando riesgos podría alcanzar el "sueño americano".

Eva decidió comprar la casa. El siguiente paso sería convencer a su esposo. Como sabía que él no estaría de acuerdo, ella realizó todos los trámites y sólo le informó cuando los documentos estaban listos. Eva relata cómo lo llevó a la casa, donde los esperaba la agente inmobiliaria, y le dijo: "es nuestra, los documentos están listos, no te queda otra que firmar", y él lo hizo. Eva insiste con orgullo en que finalmente tienen "la casa que merecen", "una casa digna de una princesa”. No lo sabía en ese momento, pero el préstamo que obtuvo era más caro que los normales. Como en el caso de Julián, era un préstamo subpreferencial, otorgado a la gente que se considera de alto riesgo, no completamente confiable. Los primeros dos años las tasas de interés eran bajas, lo que por supuesto fue el caso de la mayoría de los préstamos subpreferenciales. Durante esos primeros años no estaban abonando al capital "principal".

Para poder cumplir con los pagos, Eva rentó dos de las habitaciones de la casa. Violeta, su cuñada, vivía en la cochera y otra pareja ocupaba una de las recámaras. El valor de la casa aumentó y con ese capital Eva pudo obtener otro préstamo para comprar un vehículo. Pero sus inquilinos partieron en busca de trabajo. Eva y su familia se quedaron. Aunque sus fuentes de ingresos seguían siendo inestables, ya no podían migrar al norte para seguir los empleos. Como muchas otras familias mexicanas en la misma situación, se vieron atados a su nueva casa. Para empeorar las cosas, la hija de Eva se embarazó a los 17 años y su novio se fue a vivir a la casa. La pareja tiene ahora dos hijos. La hija de Eva trabaja en Walmart y su marido a veces consigue trabajo 
como jardinero. Eva ha tenido que hacer enormes esfuerzos para hacer los pagos, que a veces son mayores de lo que recibe de sus volátiles ingresos. Han reestructurado su deuda en dos ocasiones y ella ha tenido que pedir más préstamos a su madrina en México. Incluso Violeta ha ayudado para que su hermano y su cuñada puedan cumplir con los pagos.

\section{LA BURBUJA INMOBILIARIA Y LA CRISIS}

La burbuja inmobiliaria estimuló a las compañías constructoras a edificar un gran número de casas nuevas, especialmente en ciudades pequeñas donde podían conseguir terrenos a precios razonables. $\mathrm{La}$ mano de obra mexicana era abundante y había buenas vías de comunicación con las grandes ciudades. El incremento en la oferta de vivienda condujo a una apertura del mercado a sectores de la población que hasta entonces habían sido excluidos porque eran considerados riesgosos, incluyendo, como he mencionado, a los afroamericanos y a los latinos.

$\mathrm{Al}$ principio todos salían ganando: los agentes inmobiliarios, los bancos, las compañías constructoras y los mexicanos contratados como albañiles o para instalar techos. Las remesas a México también fueron cuantiosas en ese tiempo. Entre los mexicanos, el "sueño americano" era promovido por las agencias de bienes raíces y los bancos, que ofrecían bajas tasas de interés durante los primeros dos años, pero no especificaban que después de ese periodo los montos a pagar se incrementarían ni informaban a sus clientes que aún no estarían abonando al capital ni que tendrían que cubrir las comisiones que aparecerían en sus estados de cuenta. Convencieron a sus clientes de que el "sueño americano" se podía conseguir sólo si se tomaban riesgos.

Sin embargo, los negocios más jugosos no fueron para quienes otorgaron préstamos, para las compañías constructoras o para los agentes inmobiliarios, sino para la cadena de inversionistas que se dedicó a la venta de deudas conocida como permutas de deuda - debt swaps-. Las deudas hipotecarias, como sabemos, no se quedan en el banco que otorga el préstamo: son transferidas a terceros que están dispuestos a asumir el riesgo, que apuestan por la posibilidad de obtener mayores ganancias. Compran paquetes de deuda, entre los cuales - estén o no conscientes de ello- habrá algunas deudas impagables, pero eso no es demasiado importante porque las revenderán o las utilizarán como garantía para financiar otros negocios. Quienes adquirieron los paquetes obtuvieron a menudo ganancias monetarias exponenciales. Para complicar más el escenario, algunas empresas crearon productos financieros novedosos llamados "obligaciones de deuda colateralizada" - colateralized debt obligations (CDO) -, dentro de los cuales sólo se combinaban partes de diversos instrumentos hipotecarios con nuevas técnicas ${ }^{13}$ para el cálculo de riesgos. En 2006 el mercado se vio inundado con tales instrumentos, por un monto de casi 500000 millones de dólares.

Resulta difícil creer que miles de millones de dólares fueron generados sobre una base de deudas. Esto se debe a que en la vida cotidiana tendemos a ver la deuda como un déficit, pero la deuda también conlleva esperanzas y expectativas de pago, generalmente mayor que lo prestado. Por esta razón la deuda - los préstamos hipotecarios - fue utilizada como garantía o colateral para obtener préstamos, instrumentos bursátiles basados en hipotecas. La cadena fue sostenida por una expectativa de ganancia, así como por una creencia en que la cadena de pagos era segura y que no se rompería al estar en manos de instituciones "confiables" y mientras hubiera suficientes inversionistas con apetito de riesgo que continuaran apostando por su fortaleza.

Pero los inversionistas también sabían que quienes participan en los mercados de valores podían entrar en pánico, y en ese caso era importante ser el primero en correr en cuanto hubiera alguna indicación de

\footnotetext{
${ }^{13}$ Incluyen recategorizaciones de deudas, pero sobre todo la frag mentación de éstas.
} 
nerviosismo. Para entonces ya había reducciones de personal en un gran número de industrias estadounidenses, debido en parte a los incrementos en el precio del petróleo, a la competencia de los países asiáticos y a la mano de obra barata en los países del tercer mundo, así como a pérdidas en el sector agrícola ocasionadas por el cambio climático, todo lo cual produjo una inestabilidad aun mayor en las fuentes de empleo. Así, el número de deudores morosos empezó a aumentar. En ese momento muchos mexicanos descubrieron que sus deudas hipotecarias de interés variable habían aumentado y que, además del pago del préstamo y los intereses, le adeudaban a los bancos otra serie de cargos que incluían pagos exagerados por consultas con "expertos", asistencia legal e incluso el envío de algún fax. Los casos de bancarrota incrementaban y con ellos el número de personas que perdían sus casas.

Muchos, especialmente latinos y afroamericanos, se vieron en la imposibilidad de seguir cumpliendo con sus pagos. En ese proceso la diferenciación

(1)

racial jugó un papel determinante, ya que los préstamos a la población de origen mexicano, o en este caso los afroamericanos y los latinos, fueron considerados de alto riesgo. Por tanto, se les otorgaron casi siempre préstamos subpreferenciales, que podían ser hasta cinco veces más costosos que los préstamos normales. Las tasas de interés eran variables e incrementaban en el segundo año o en el tercero. Para atraerlos al esquema de crédito, les prometieron tasas bajas durante los primeros años sin informarles que después aumentarían.

En California, los precios de las casas se elevaron $51 \%$ entre finales de 2003 y mediados de 2006. El incremento en valor creó un amortiguador con el capital residual - equity buffer - que los beneficiarios del préstamo podían utilizar para refinanciar su hipoteca cuando el impacto de los pagos excedía su capacidad de pago. Un estudio realizado por la Consumers Federation in America en enero de 2008 reporta que más de una tercera parte de quienes obtuvieron préstamos para comprar una casa en California recurrieron también a un segundo préstamo basado en la primera hipoteca (Black, Boehm y DeGennaro, 2011; Hudson y Reckard, 2005).

Un estudio de The Wall Street Journal (Brooks y Simon, 2007) encontró que, a nivel nacional, $61 \%$ de quienes obtuvieron préstamos subpreferenciales realmente habrían tenido derecho a un préstamo normal si se hubiera tomado en cuenta su historial de crédito. A su vez, tanto el análisis de la Reserva Federal como un estudio del Center for Responsible Lending revelan que los altos costos cobrados en esos préstamos no se justificaban (Bernanke, 2006; Gruenstein y Li, 2006), y sugieren que en muchos casos esos altos costos eran atribuibles a la discriminación racial. Los préstamos subpreferenciales de altos intereses fueron otorgados a más latinos, afroamericanos y en algunas regiones a asiáticos que a angloamericanos. De acuerdo con datos de la Association of Community Organizations for Reform Now (ACORN), en California 55.3\% de los solicitantes afroamericanos de préstamos y $46.6 \%$ de los hispanos recibieron préstamos subpreferenciales, en comparación con $20.4 \%$ de los solicitantes "blancos". El doble de hispanos recurrieron a préstamos subpreferenciales de refinanciamiento en relación con los "blancos" estadounidenses.

Entre noviembre de 2006 y el mismo mes de 2007, los precios de las casas en California cayeron entre 12 y $20 \%$, según la zona y el tipo de casa. Con el "enfriamiento del mercado", los deudores hipotecarios que habían optado por segundas hipotecas se encontraron con deudas mayores que el valor de sus casas. Muy pocos podían venderlas o refinanciarlas. Los esfuerzos posteriores de la industria hipotecaria por modificar los préstamos fueron claramente insuficientes. Conforme la situación empezó a ser del conocimiento público, el pánico se apoderó de Wall Street con la consecuente bancarrota de no pocas grandes empresas y muchas más pequeñas. Miles de millones de dólares se evaporaron en unas cuantas semanas, no sólo los de los grandes inversionistas sino los de una multitud de pequeños deudores, entre ellos un número significativo de mexicanos. 
$\mathrm{Al}$ menos en las etapas iniciales, los esfuerzos del gobierno por enderezar la economía estuvieron orientados no tanto a enmendar errores sino a recuperar la confianza de los inversionistas e incrementar el dinero circulante para estimular el consumo.

\section{HACIENDO MALABARES PARA ENFRENTAR EL SOBREENDEUDAMIENTO}

La crisis financiera dejó al descubierto una serie de mecanismos a través de los cuales se asigna el valor y se establecen las equivalencias en los mercados financieros, y puso de manifiesto una economía virtual en la que la riqueza aparece y desaparece como por arte de magia. Vivimos en una economía construida sobre arenas movedizas, dentro de la cual las relaciones sociales y la confianza juegan un papel fundamental. Con la crisis, los trabajadores de la construcción se vieron obligados a buscar trabajo en otros lugares. Algunos encontraron empleo como mecánicos, meseros o jardineros, pero muchos regresaron al trabajo agrícola, en el que el cambio climático también mermó sus opciones laborales. Heladas, inundaciones e incendios afectaron a este sector, que ya estaba recibiendo una cantidad importante de migrantes. No ha sido fácil encontrar empleos.

Un porcentaje relativamente bajo de mexicanos adquirió bienes raíces, pero muchos compraron bienes a crédito en mueblerías y negocios locales, y un número importante utilizaba tarjetas de crédito y débito, aunque ésta era una posibilidad remota para los indocumentados. Todos interactuaban diariamente con los efectos directos e indirectos de estos sistemas financieros, los cuales se acoplan

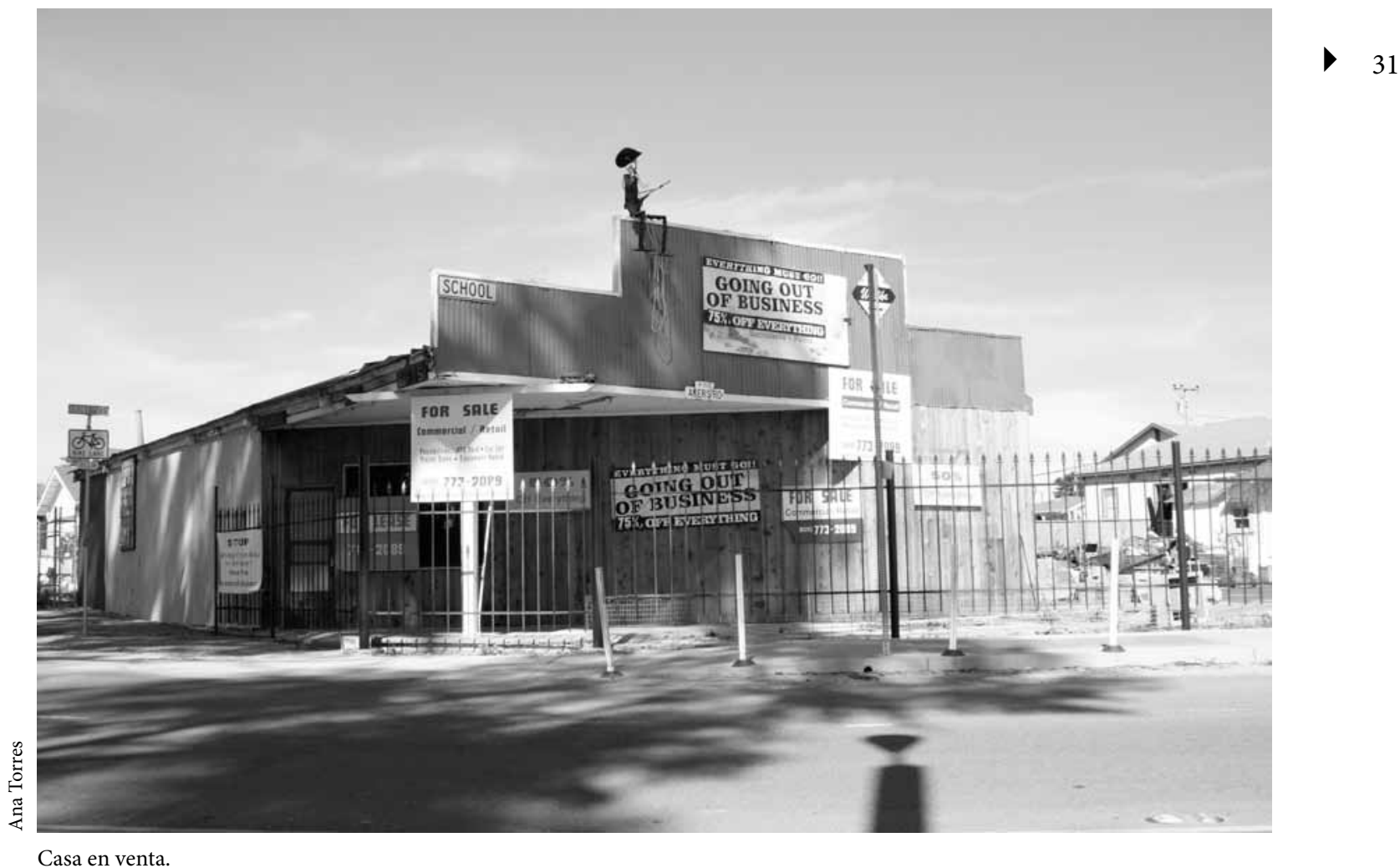


nítidamente a los tipos de estructuración que encuentran $-\mathrm{y}$ contribuyen a reproducir- en los campos agrícolas donde trabajan, con las formas de consumo, de pago y sistemas tributarios. También se traslapan con otras economías, que podemos llamar tercermundistas o atrasadas, que sin embargo sostienen el andamiaje financiero translocal dentro del cual operan. ${ }^{14}$

Por otro lado, el crecimiento exponencial de las remesas a México que se observó en años anteriores sufrió un fuerte descenso. No obstante, es de reconocer que parte de éste se explica por las expectativas que en ese tiempo generaron las discusiones políticas en torno a las posibilidades de una nueva amnistía para los inmigrantes ilegales. Muchos mexicanos en California empezaron a ahorrar para pagar a intermediarios que les ofrecían ayudarles a obtener los ansiados documentos que los legalizarían. Esto trajo consigo una reducción en el monto de las remesas a México. Pero es claro que un alto porcentaje de inmigrantes mexicanos estaban empleados en el sector de la construcción y perdieron sus empleos, además de los estragos causados por la crisis de la deuda y su efecto dominó. Los mexicanos que perdieron sus casas y el dinero invertido en ellas también se vieron limitados en su capacidad de continuar enviando remesas. De hecho, en muchos casos la reducción en las remesas inició en el momento en el que comenzaron a destinar sus ahorros al pago de sus préstamos. La madre de Enriqueta murió en 2004, así que ella ya no tiene que enviarle dinero, pero también ha dejado de enviar fondos para el mantenimiento de su casa en el pueblo en el que vivía. Para Violeta no ha sido fácil conseguir empleo, pero no quiere regresar a México. Sus experiencias negativas durante su último viaje la hacen pensar que en su país no podría ganar lo suficiente para sobrevivir.

\footnotetext{
${ }^{14}$ Recordemos no sólo la relevancia de las remesas inversas, sino el sostén que las configuraciones socioeconómicas translocales proporcionan para la supervivencia de los mexicanos en Estados Unidos.
}

El lector laico podrá argumentar que todos los que perdieron sus casas en la crisis hipotecaria estaban sobreendeudados. Algunos, como Eva y Enriqueta, que gastan más de $30 \%$ de sus ingresos en pagar deudas, quizá entrarían en esa categoría. Sin embargo, Enriqueta nunca ha tenido la menor duda de que los esfuerzos que ha hecho para pagar su casa han valido la pena. Aunque en su pueblo en México podría haber conseguido una casa más grande con un jardín, ya ha establecido su vida en Estados Unidos. Al igual que otros que probablemente no cumplirían con los criterios oficiales para "calificar" para préstamos, toma dinero de aquí y de allá, trabaja horas extra, hace tamales que vende a sus amigos, vive en una recámara que comparte con su esposo ahora que sus hijos se casaron y cambiaron de residencia y renta las otras habitaciones a mexicanos que van a California en busca de trabajo. Se siente apoyada por su red de amistades en la Iglesia Evangélica, de la cual se ha hecho devota. Habla de las dificultades que le causa cumplir con sus pagos, pero no se siente sobreendeudada.

Aunque Eva está consciente de que está endeudada más allá de sus posibilidades, no se arrepiente de haber pedido un préstamo ni siente que las puertas se le han cerrado. Seguirá luchando. En este momento no puede rentar habitaciones porque sólo tiene una disponible, ya que su hija ocupa una con su esposo y su niño, y en la otra vive su hijo. Prefiere dejar la habitación restante vacía para cuando su madrina vaya a visitarla, ya que constantemente recurre a sus préstamos. También ha tenido que pedir dinero prestado a su padre y ha reestructurado su deuda en dos ocasiones. Su convicción de que ella y su familia merecen una mejor vida le da la energía para seguir adelante. Afortunadamente encontró empleo en Walmart y su esposo ha conseguido pequeños contratos aquí y allá porque la gente necesita hacer reparaciones en sus casas y no puede pagar a constructores establecidos. Al reflexionar sobre su situación, Eva comenta que a pesar de que el objetivo de las mujeres que emigran no era hacerse millonarias, sí buscaban dejar atrás la pobreza. Pensaban 
que emigrando al "norte" encontrarían ese progreso, pero han enfrentado muchas dificultades. Sin embargo, sigue teniendo fe en las posibilidades de tener una mejor vida en Estados Unidos.

Irónicamente, Julián —el único miembro del grupo que realmente cumplía con los criterios para "calificar" para un préstamo, excepto quizá por su nacionalidad - fue quien dejó de hacer sus pagos. La "lógica" empresarial que aprendió en su trabajo en la plantación de brócoli y el consejo de un profesional lo llevaron a aceptar un negocio más riesgoso pero, como los demás, se vio forzado a acudir a sus redes de contactos en México y vendió el terreno de su familia para tratar de superar la situación. Eva y Violeta han recurrido a redes de contactos para conservar sus casas, especialmente en la forma de remesas inversas de México. Han conseguido préstamos de amigos y familiares, la mayoría de los cuales no han pagado y posiblemente no podrán pagar. Además, Violeta, Enriqueta, Julián y Enrique han recibido "subsidios" en forma de atención no remunerada a sus familiares más cercanos, como sus cónyuges, sus hijos y sus padres. Esto muestra la pluridimensionalidad de los flujos, que no van sólo de Estados Unidos a México sino también de México a Estados Unidos. Con ellos vienen asimismo restricciones al flujo que se activa en los diferentes códigos de la interacción económica transnacional. Tal es el caso, como hemos detallado aquí, del género.

Las redes de contactos que cruzan fronteras nacionales también constituyen espacios en los que los migrantes aprenden a actuar social y financieramente en la sociedad estadounidense. Los parámetros sociales, culturales y morales que se reproducen al interior de tales redes le dan forma y contenido a las transacciones monetarias. De ahí que los roles de género estén entretejidos en el tapiz de la economía cotidiana tanto en México como en Estados Unidos, y que contribuyan a procesos en los que se significan y sopesan las transacciones y se evalúan las relaciones sociales. Las mujeres se enfrentan a la necesidad de hacer malabares de una economía a la otra y de hacer cálculos culturales que le infunden valor a los escenarios financieros en la interacción y el juego recíproco de las geografías.

Sin embargo, los flujos de información al interior de esas redes son limitados. Muchos mexicanos no pudieron negociar préstamos estándar porque no contaban con información acerca del manejo de recursos financieros y cayeron en las avaras manos de banqueros e intermediarios. En este caso, los cálculos culturales predominantes en la sociedad estadounidense fueron instrumentales. Como hemos visto, la identidad de latinos o de afroamericanos lleva consigo etiquetas de "no confiable" o "riesgoso", lo que implicó costos elevados para los solicitantes de préstamos. Esto revela uno de los aspectos esenciales de los sistemas financieros, que tendemos a obviar en nuestros análisis. Es de suma importancia tomar en cuenta que en las transacciones financieras se entrelazan transacciones y valores monetarios y no monetarios. El tejido social llega a ser parte de la transacción al mismo tiempo que se reproduce en ella. En el caso que analizamos, podemos constatar que la economía de los mexicanos en Estados Unidos vive y respira de este tejido social, en el cual se mueven distintos regímenes de valor. De forma simultánea, interactúa cotidianamente con otras economías locales y transnacionales en las que también se cruzan distintos regímenes de valor. Como pudimos observar, ello implica la realización de una gama de malabarismos, en particular cuando se enfrenta una crisis de las dimensiones de la que estamos viviendo en estos tiempos.

\section{BIBLIOGRAFÍA}

Appadurai, Arjun (ed.), 1986, The Social Life of Things: Commodities in Cultural Perspective, Cambridge University Press, Cambridge.

BBva Bancomer, 2010, México. Situación migración, Servicio de Estudios Económicos de la Fundación BBva Bancomer, México.

Bernanke, Ben, 2006, "Community Development Financial Institutions: Promoting Economic Growth and Opportunity", ponencia, Remarks to the Opportunity 
Finance Network's Annual Conference, 1 de noviembre, Washington, D. C.

Black, Harold, Thomas Boehm y Ramon P. DeGennaro, 2001, "Is There Discrimination in Mortgage Pricing? The Case of Overages", en Working Paper 2001-4a, Reserva Federal del Banco de Atlanta, Atlanta.

Bourdieu, Pierre, 1994, Language and Symbolic Power, Polity Press, Cambridge.

Brooks, Rick y Ruth Simon, 2007, "Subprime Debacle Traps even very Credit-Worthy”, en Wall Street Journal, 3 de diciembre, Nueva York.

Gruenstein, Debbie y Wei Li, 2006, Unfair Lending: The Effect of Race and Ethnicity on the Price of Subprime Mortgages, Center for Responsible Lending, Carolina del Norte.

Hernández Romero, Manuel Adrián, 2010, “Estabilización de trabajadores agrícolas migrantes: ¿base para su plena proletarización?", tesis de doctorado, Centro de Investigaciones y Estudios Superiores en Antropología Social, México.
Hudson, Mike y E. Scott Reckard, 2005, "More Homeowners with Good Credit Getting Stuck with HigherRate Loans", en Los Angeles Times, 24 de octubre, Los Ángeles.

Keen, Steve, 2001, Debunking Economics: The Naked Emperor of Social Sciences, Zed Books, Nueva York.

Palerm, Juan Vicente, 2007, "De colonias a comunidades. La evolución de los asentamientos mexicanos en California rural", ponencia, Coloquio sobre migración $y$ movilidad laboral, 14 y 15 de junio, México.

Villarreal, Magdalena (coord.), 2004, Antropología de la deuda: crédito, ahorro, fiado y prestado en las finanzas cotidianas, Centro de Investigaciones y Estudios Superiores en Antropología Social, Porrúa, Cámara de Diputados, México.

, 2011, "Mexicanas en California: jinetes de economías en crisis", en Adriana Sandoval (coord.), Sociedad y culturas regionales. Problemas locales, miradas globales, Universidad Nacional Autónoma de México, México. 